\title{
Relationship Between Viscoelastic and Physicochemical Parameters in Cebreiro Cheese (PDO)
}

\author{
Inmaculada Franco ${ }^{1}$, Verónica Bargiela ${ }^{2}$, Javier Carballo ${ }^{1} \&$ Clara A. Tovar ${ }^{2}$ \\ ${ }^{1}$ Área de Tecnología de los Alimentos, Universidad de Vigo, Facultad de Ciencias de Ourense, Ourense, Spain \\ ${ }^{2}$ Departamento de Física Aplicada, Universidad de Vigo, Facultad de Ciencias de Ourense, Ourense, Spain \\ Correspondence: Inmaculada Franco, Área de Tecnología de los Alimentos, Universidad de Vigo, Facultad de \\ Ciencias, Ourense 32004, Spain. Tel: 34-988-387-055. E-mail: inmatec@uvigo.es
}

Received: December 19, 2012 Accepted: February 22, 2013 Online Published: April 23, 2013

doi:10.5539/jfr.v2n3p1

URL: http://dx.doi.org/10.5539/jfr.v2n3p1

\begin{abstract}
Rheological and physicochemical analyses of Cebreiro cheese were carried out. Four samples of each of three batches of cheese from different commercial producers were analyzed. Mechanical spectra data were obtained from frequency sweeps at $20^{\circ} \mathrm{C}$, a quality factor $Q$ and fractal dimension $D f$ were obtained from these rheological data. Moisture content, physicochemical ( $\mathrm{pH}$ and titratable acidity) and proteolysis-related parameters were also measured. Analysis of the temperature dependence of the complex viscosity also enabled characterization of the activation energy of the three batches. The different viscoelastic parameters were highly consistent and structural differences between the different batches were observed. As regards the chemical composition level, high correlations between moisture, titratable acidity, nitrogen fractions and several viscoelastic parameters were observed. In general, casein networks were more extensive and elastic in batches with higher titratable acidity and moisture.
\end{abstract}

Keywords: acid coagulation, casein network, fractal dimension, loss tangent, Cebreiro cheese, quality factor

\section{Introduction}

Cebreiro is a traditional variety of cheese made in the north-east of Spain from pasteurized cow's milk. The cheese, which was awarded Protected Denomination of Origin (PDO) status in 2004 (Xunta de Galicia, 2004), is soft and creamy, with no holes, intensely crumbly and melts on the palate. Manufacture of this cheese is characterized by a predominantly acidic coagulation and prolonged whey drainage (Lafuente, Carballo, González Prieto, \& Martín Sarmiento, 1995).

The physical properties of cheese are influenced by a number of factors including: milk composition, milk quality, temperature, rate and extent of acidification by the starter bacteria, $\mathrm{pH}$ history of cheese from coagulation process to final ripening, concentration of $\mathrm{Ca}$ salts (proportions of soluble and insoluble forms), extent and type of proteolysis and other ripening reactions (Lucey, Mishra, Hassan, \& Johnson, 2005).

Cheese is a viscoelastic dairy gel, and the texture of the product is important because it is this property by which the consumer first identifies and judges the specific variety. The total $\mathrm{Ca}$ content, $\mathrm{pH}$ and proteolysis are critical parameters that influence the textural and physical properties of cheeses (Lawrence, Creamer, \& Gilles, 1987; Lucey \& Fox, 1993; Watkinson et al., 2001; Lucey, Johnson, \& Horne, 2003; Sheehan \& Guinee, 2004). The texture of a cheese is determined primarily by its $\mathrm{pH}$ and the ratio of intact casein to moisture (Antoniou, Petridis, Raphaelides, Ben Omar, \& Kesteloot, 2000). The $\mathrm{pH}$ directly determines the number and balance of the charge distribution of amino acids on casein molecules (Swaisgood, 1993). The amount of insoluble Ca in cheese plays a key role in controlling the texture as it has a direct influence on casein-casein interactions (Lucey et al., 2003). Caseins possess important structural features that affect gelation, such as the variation in the degree of phosphorylation, glycosylation, hydrophobicity and amphipathic structures (Rao, 2007).

At the molecular level, cheese gelation involves the formation of a continuous network of casein molecules, in which the stress-resisting bulk properties (solid-like behaviour) are imparted by a framework of protein chains that extend throughout the gel phase. Acidification causes two major processes to occur. Firstly, the calcium and phosphate are dissolved out of the micelle as a result of protonation of the ionized phosphate groups, and the structure of the micelle is profoundly altered (Damodaran \& Paraf, 1997). When the isoelectric point is 
approached, caseins precipitate isoelectrically, and a three-dimensional solid-like network is formed by charge neutralization. The network formed may be designated as being fine-stranded or particulate (Rao, 2007). The microstructure of particulate gels consists of large aggregates, which are opaque and have a low water holding capacity. Acid milk gels are examples of "particulate gels" and have been described as fractal in nature.

To date, no information has been reported regarding the influence of physicochemical parameters on the viscoelastic properties of the Cebreiro cheese (PDO). The objectives of the present study were therefore: (a) to characterize the rheological properties of batches of Cebreiro cheese made by different manufacturers, and (b) to relate these properties with to physicochemical and proteolytic parameters.

Apart from helping to improve the quality of this variety of cheese, the results of this study will contribute data on the biochemical and rheological characters of fresh acid curd cheeses in general.

\section{Materials and Methods}

\subsection{Samples}

Three batches of Cebreiro cheese manufactured by three different producers following the industrial method described by Lafuente et al. (1995), in compliance with PDO status, were analyzed in the present study. Four samples were taken from each batch on different days. Each cheese sample consisted of one whole cheese. Samples were transported to the laboratory under refrigeration (below $4^{\circ} \mathrm{C}$ ) and were subjected to rheological test measurements on the day of sampling.

\subsection{Moisture, pH, Titratable Acidity and Nitrogen Fractions}

The water contents of the cheese samples were determined following the FIL-IDF 4A: 1982 standard method. The $\mathrm{pH}$ and titratable acidity were measured following the 14.022 AOAC method (1980). The total nitrogen content (TN) was determined by the Kjeldahl method, as described in the FIL-IDF 20B: 1993 standard. Water-soluble nitrogen (WSN) was determined by fractionation of the cheese samples with water, according to Kuchroo and Fox (1982). The trichloroacetic acid soluble nitrogen (TCASN) fraction was prepared by adding $7.5 \mathrm{~mL}$ of an aqueous solution of $48 \%$ (w/v) trichloroacetic acid to $22.5 \mathrm{~mL}$ of water-soluble extract; the mixture was allowed to stand at room temperature for $30 \mathrm{~min}$ and then filtered through Whatman No. 42 filter paper. The phosphotungstic acid soluble nitrogen (PTASN) test was carried out by adding $14 \mathrm{~mL}$ of $3.95 \mathrm{M}$ sulphuric acid and $6 \mathrm{~mL}$ of $33.3 \%(\mathrm{w} / \mathrm{v})$ phosphotungstic acid to $20 \mathrm{~mL}$ of water soluble extract; the mixture was allowed to stand at $4^{\circ} \mathrm{C}$ overnight and subsequently filtered through Whatman No. 542 filter paper. Aliquots from both fractions were then analyzed by the Kjeldahl method. All measurements were made in duplicate.

\subsection{Dynamic Rheological Measurements}

All rheological measurements were performed with a Bohlin CVO controlled-stress rheometer (Bohlin Instruments, Inc. Cranbury, NJ). The measurement system used was a $20 \mathrm{~mm}$ parallel-plate. Cheese samples were cut into cylindrical samples of $20 \mathrm{~mm}$ diameter and $1 \mathrm{~mm}$ thick. Samples were placed between the parallel plates of the rheometer; the upper plate was lowered and stopped at a final gap of $1.0 \mathrm{~mm}$ from the lower plate. Any excess sample protruding beyond the upper plate was carefully removed. Samples were allowed to rest for $15 \mathrm{~min}$ before analysis to ensure both thermal and mechanical equilibrium at the time of measurement. A thin film of Vaseline ${ }^{\circledR}$ petroleum jelly (purissimum Codex) was gently applied to the edge of each exposed sample to prevent moisture loss. No evidence of specimen slippage at the bottom plate was detected. The temperature of the lower plate was maintained at $20.0 \pm 0.1^{\circ} \mathrm{C}$ in a Bohlin Rheology fluid circulating bath (also from Bohlin Instruments, Inc.) and controlled by use of a computer.

To determine the linear viscoelastic (LVE) region, a stress sweep (angular frequency $6.28 \mathrm{rad} / \mathrm{s}$ ) was performed in the range of $10-2000 \mathrm{~Pa}$ at $20^{\circ} \mathrm{C}$. Changes in storage $\left(G^{\prime}\right)$ and loss modulus $\left(G^{\prime \prime}\right)$ were recorded. The procedure for determining the limit values of stress $\left(\sigma_{\max }\right)$ and strain $\left(\gamma_{\max }\right)$, was explained in a previous study in which creep and recovery tests were used to corroborate the amplitude of LVE range (Campo-Deaño \& Tovar, 2009). Frequency sweeps were carried out on the samples in the $0.1-10 \mathrm{~Hz}$ range at $0.5 \%$ strain, and changes in $G$ ' and $G$ ' moduli were recorded at $20^{\circ} \mathrm{C}$.

The values of complex viscosity $\left(\mu^{*}=G^{*} / \omega\right)$ for all samples from the three batches were obtained at five temperatures, at $\omega=6.3 \mathrm{rad} / \mathrm{s}$ and a fixed strain of $0.5 \%$ (within the LVE range). The selected temperatures were $20,22,24,26,28$, and $30^{\circ} \mathrm{C}$.

\subsection{Statistical Analyses}

Significantly different means $(\mathrm{P}<0.05)$ were compared by the least squares difference (LSD) test by use of the statistical software Statistica 5.1 for Windows (StatSoft Inc., 1996, Tulsa, OK, USA). Statistical correlations between 
the biochemical and the rheological parameters were determined by multiple regression with confidence intervals of $95 \%(\mathrm{P}<0.05), 99 \%(\mathrm{P}<0.01)$ and $99.9 \%(\mathrm{P}<0.001)$, by use of the Statistica 5.1 software.

\section{Results and Discussion}

\subsection{Biochemical Parameters}

The values of the Total Solid (TS) contents, physicochemical parameters and nitrogen fractions of Cebreiro cheese are shown in Table 1. The moisture content is consistent with values reported for the same cheese, by other authors (Lafuente et al., 1995; Fresno, Prieto, Urdiales, Martín Sarmiento, \& Carballo, 1995). The TS values were significantly lower $(\mathrm{P}<0.05)$ in batch $\mathrm{B}$ samples than in batch $A$ and $C$ samples. This variation may be caused by the differences in intensity of whey drainage used by the different cheesemakers. Rearrangement of casein micelles during the whey draining process causes shrinkage of the casein matrix and subsequent expulsion of whey from curd. The rate and extent of whey drainage controls the moisture and lactose contents of curd (Castillo, Lucey, \& Payne, 2006), which effects the moisture and pH of the cheese, and consequently the texture.

The low $\mathrm{pH}$ of Cebreiro cheese is due to the acid coagulation processes involved in production of the cheese (Lafuente et al., 1995). The $\mathrm{pH}$ values were similar in the three batches studied and are within the range described by other authors (Lafuente et al., 1995; Fresno et al., 1995).

Taking into account the observed $\mathrm{pH}$ values, similar values of titratable acidity would be expected, however the $\mathrm{pH}$ of batch $A$ samples was significantly lower $(\mathrm{P}<0.05)$ than the $\mathrm{pH}$ of batch $B$ and $C$ samples. This may be attributed to different draining intensities. The TS content and the titratable acidity were negatively and significantly correlated $(\mathrm{P}<0.01, \mathrm{r}=-0.72)$ (Table 5 ). The long coagulation periods with intense acidification induce extensive demineralization of the casein micelles. The large mineral losses in the whey (greater drainage in batch $A$ samples) may be related to the buffering capacity of the mass, which would be lower in batch $A$, resulting in lower values of titratable acidity.

The values of the different nitrogen fractions in Cebreiro cheese indicate that this cheese undergoes a low level of proteolysis. These values are within the range of those observed in other unripe Spanish cheese and similar to those determined by other authors for this variety of cheese (Lafuente et al., 1995). The rennet that remains in the curd after whey drainage is responsible for the initial attack on caseins, forming large-sized peptides which are later degraded by the action of microbial and milk autochthonous enzymes. The low values of WSN and TCASN may be related to the small quantities of rennet used in the elaboration of this cheese.

The WSN and TCASN contents were positively and significantly correlated $(\mathrm{P}<0.05)$ with moisture content $(\mathrm{r}$ $=0.77$ and $\mathrm{r}=0.87$, respectively) and titratable acidity values $(\mathrm{r}=0.78$ and $\mathrm{r}=0.79$, respectively) (Table 5). The values of WSN and TCASN were significantly lower $(\mathrm{P}<0.05)$ in the batch $A$ cheeses than in batch $B$ and $C$ cheeses. This appears to be affected by the moisture content and therefore by the rennet retained in the curd.

Table 1. Changes in total solids, $\mathrm{pH}$, titratable acidity and nitrogen fractions in three batches of Cebreiro cheese

\begin{tabular}{llll}
\hline & A & B & C \\
\hline Total Solids* & $43.78 \pm 0.88^{\mathrm{a}}$ & $38.23 \pm 2.37^{\mathrm{b}}$ & $41.41 \pm 1.97^{\mathrm{a}}$ \\
pH & $4.31 \pm 0.06^{\mathrm{a}}$ & $4.21 \pm 0.05^{\mathrm{a}}$ & $4.22 \pm 0.13^{\mathrm{a}}$ \\
Titratable acidity***$^{*}$ & $1.06 \pm 0.08^{\mathrm{a}}$ & $1.34 \pm 0.13^{\mathrm{b}}$ & $1.25 \pm 0.05^{\mathrm{b}}$ \\
TN** $^{*}$ & $2.37 \pm 0.13^{\mathrm{a}}$ & $2.27 \pm 0.13^{\mathrm{a}}$ & $2.24 \pm 0.08^{\mathrm{a}}$ \\
WSN*** $^{*}$ & $1.31 \pm 0.13^{\mathrm{a}}$ & $1.76 \pm 0.21^{\mathrm{b}}$ & $1.72 \pm 0.29^{\mathrm{b}}$ \\
TCASN*** $_{\text {PTASN*** }}$ & $0.64 \pm 0.06^{\mathrm{a}}$ & $1.02 \pm 0.09^{\mathrm{b}}$ & $0.89 \pm 0.06^{\mathrm{c}}$ \\
\hline
\end{tabular}

${ }^{a}$ Means in the same file not followed by the same letter differed significantly $(\mathrm{P}<0.05)$;

* Expressed as g/100 g cheese;

** Expressed as g /100 g Total Solids*;

*** Expressed as g/100 g Total Nitrogen. 


\subsection{Oscillatory Tests at Small Strain and Constant Temperature}

\subsubsection{Amplitude Sweeps}

These tests enable discrimination of two different regions: a linear viscoelastic (LVE) region, in which the viscoelastic moduli: complex modulus, $\left(G^{*}\right)$ storage modulus $\left(G^{\prime}\right)$ and viscous $\left(G^{\prime \prime}\right)$ are almost constant, and a non linear region in which $G$ ' began to decrease while $G$ "' began to increase, and finally both moduli tended to cross over).

As long as the $\gamma$-amplitudes are still below the limiting value $\gamma_{L}$, the structure of the sample remains stable under these conditions, and viscoelastic parameters possess physical meaning (Barnes, Hutton, \& Walters, 1998). The limiting values of $\sigma_{L}$ and $\gamma_{L}$ in batches $A, B$ and $C$ are similar and statistically undistinguishable $(\mathrm{P}<0.05)$ at $20^{\circ} \mathrm{C}$ (Table 2). Moreover in all samples $\gamma_{L}<1 \%$, a finding that is consistent with the corresponding $\gamma_{L}$ values for other Galician cheeses produced by enzymatic coagulation, and with a short ripening time (Tovar, Franco, Riveiro, Romaní, \& Carballo, 2004a).

The $G^{*}$ values for the three batches were not able to be distinguished because of the degree of experimental uncertainty (Table 2). $G^{*}$ is related to the rigidity of the material, and can be used as a measure of the gel strength in different protein gels and their derivative products (Campo-Deaño \& Tovar, 2009). Cheese appears to have a three-dimensional network, but it also flows, and therefore $G^{*}$ is a measure of the "strength" of the interactions between the flowing units (Gabriele, de Cindio, \& D'Antona, 2001) such as micelle aggregates. Thus the firmness of all samples of Cebreiro cheese was high and similar, since it is an unripe cheese, and therefore the degree of proteolysis was low (Table 1).

However it was possible to distinguish the loss tangent $(\tan \delta)$ within the LVE region $\tan \delta=G{ }^{\prime \prime} / G$ ' is the ratio of the viscous to elastic properties, and is associated with relaxation of bonds in the gel during deformation (Lucey, 2002). The value of $\tan \delta$ was higher in batch $A$ than in batch $B$ and $C$ cheeses (Table 2). This may be attributed to a partial loosening of bonds within and between casein molecules in the gel network of batch $A$ cheeses. On the contrary $\tan \delta$ was significantly lower in batches $B$ and $C$, in which the titratable acidity is significantly higher (Table 1), indicating that their casein matrices are more elastic than in batch $A$. The Horne model suggests that acidification of milk leads to solubilization of colloidal calcium phosphate $(C C P)$, which loosens the bridging between caseins, which also disturbs the delicate balance between attraction and repulsion that governs micellar integrity (Horne, 1998). Moreover, solubilization of CCP appears to alter the balance between viscous and elastic components (Lucey, 2002), but not the overall rigidity of the network; this may explain the significant influence of titratable acidity on $\tan \delta$ but not on $\mathrm{G}^{*}$. The low losses of $C C P$ in $B$ and $C$ batches due to the lower degree of demineralization during whey drainage fortified the internal structure of the micelles; as a result the solid-like character of casein networks increased and $\tan \delta$ decreased (Table 2).

Table 2. Linear Interval Limit values: shear stress, shear strain, complex modulus and loss tangent, for the three batches of Cebreiro cheese, from stress sweep test at $1 \mathrm{~Hz}$ and $20^{\circ} \mathrm{C}$

\begin{tabular}{llll}
\hline & $\mathbf{A}$ & $\mathbf{B}$ & $\mathbf{C}$ \\
\hline $\mathbf{G}^{*}(\mathbf{k P a})$ & $25.0 \pm 9.3^{\mathrm{a}}$ & $27.2 \pm 6.0^{\mathrm{a}}$ & $42 \pm 15^{\mathrm{a}}$ \\
$\boldsymbol{\sigma}_{\lim }(\mathbf{P a})$ & $125 \pm 12^{\mathrm{a}}$ & $154 \pm 15^{\mathrm{a}}$ & $154 \pm 15^{\mathrm{a}}$ \\
$\boldsymbol{\%} \boldsymbol{\gamma}_{\lim }$ & $0.55 \pm 0.22^{\mathrm{a}}$ & $0.59 \pm 0.14^{\mathrm{a}}$ & $0.40 \pm 0.16^{\mathrm{a}}$ \\
$\boldsymbol{t a n} \boldsymbol{\delta}$ & $0.316 \pm 0.011^{\mathrm{a}}$ & $0.281 \pm 0.012^{\mathrm{b}}$ & $0.290 \pm 0.001^{\mathrm{b}}$ \\
\hline
\end{tabular}

${ }^{a}$ Values in the same file not followed by the same letter differed significantly $(\mathrm{P}<0.05)$.

\subsubsection{Frequency Sweeps}

The frequency dependence of $G^{\prime}$ and $G^{\prime \prime}$ can provide valuable information about the structure of a gel. A material whose $G$ ' and $G$ ' are frequency-independent, with $G^{\prime}>G^{\prime}$, is a true gel. In contrast strong frequency dependence suggests a material structure with molecular entanglements (Ross-Murphy, 1984).

Mechanical spectra for batches $A, B$ and $C$ are shown in Figure 1. By performing a series of frequency sweep tests at small strain amplitude $(0.5 \%)$, it was possible to confirm that the all samples of Cebreiro cheese behaved as solid-like materials $\left(G^{\prime}>G^{\prime}\right.$ '), with $G$ ' one order of magnitude greater than $G$ ', (Figure 1); this was consistent with the findings of Fernández-Abalat, Fernández, and Méndez (2006). 


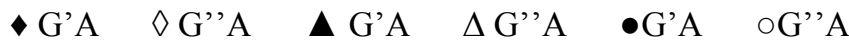
power law fit

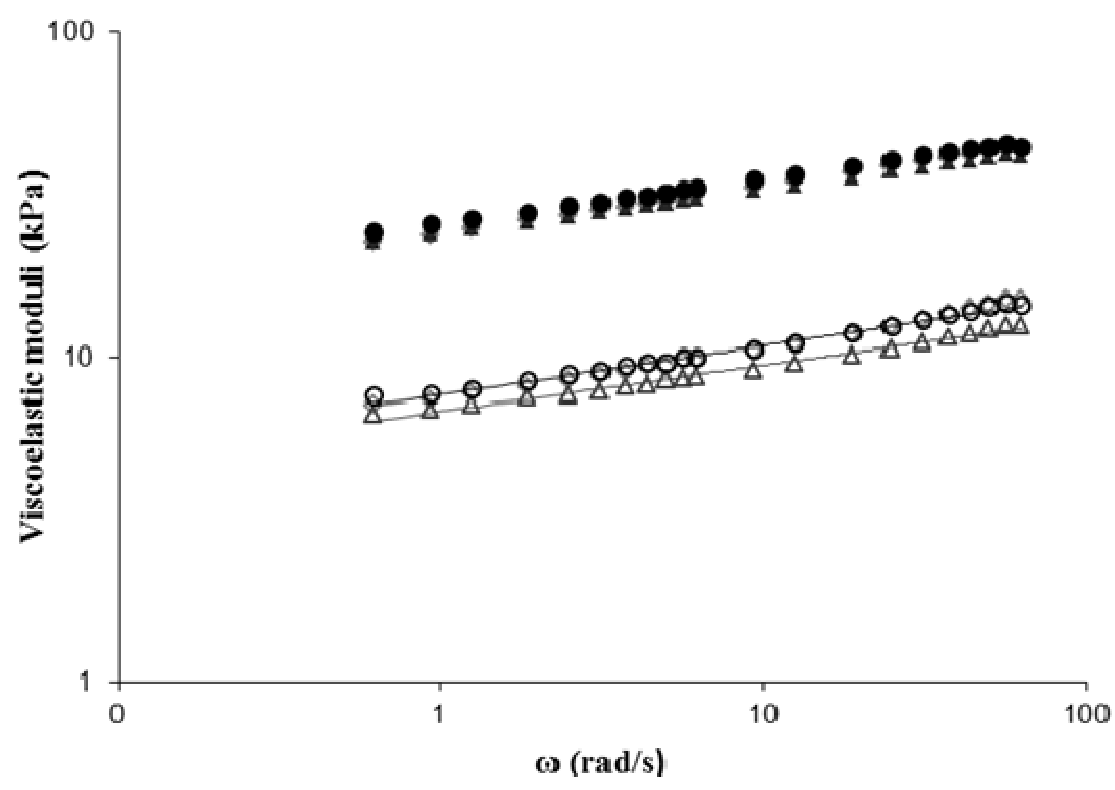

Figure 1. Mechanical spectra data for the three batches of Cebreiro cheese at $20^{\circ} \mathrm{C}$

Frequency sweep tests were used to fit $G^{\prime}$ and $G$ ' to the power law (Equations 1 and 2). $G$ ' is a measure of the deformation energy stored by the sample during the shear process, and represents the elastic behavior of a material. $G$ " 'is a measure of the deformation energy used up by the sample during the shear process, and so lost by the sample; it represents the viscous behavior of the material.

$$
\begin{aligned}
G^{\prime} & =G_{0}^{\prime} \omega^{n^{\prime}} \\
G^{\prime \prime} & =G_{0}^{\prime \prime} \omega^{n^{\prime \prime}} \\
G^{*} & =A_{n} \omega^{n}
\end{aligned}
$$

where $A_{n}=\left(G_{0}{ }^{2}+G_{0}{ }^{\prime 2}\right)^{1 / 2}$. The values of $G^{\prime}$ and $G^{\prime \prime}$ were similar in all three batches at all range of frequencies; thus the overall rigidity of the casein networks is statistically indistinguishable (Table 3 and Figure 1). However there were significant differences in the $n$ ' and $n$ ' "parameters (Table 3). The difference between the strong (true) gel and the weak gel can be established by mechanical spectroscopy (Clark \& Ross-Murphy, 1987). In the former, the molecular rearrangements within the network were reduced over the time scales analyzed; $G$ ' and $G$ ', are almost independent of $\omega$ (low and similar $n$ ' and $n$ " parameters). According to this, the gel characteristics of batches $B$ and $C$ (with lower $n$ ' and $n$ " parameters) were better and these were therefore stronger gels than batch $A$ (Table 3). Moreover the $n$ ' and $n$ "' parameters were negatively and significantly correlated $(\mathrm{P}<0.01)$ with titratable acidity values $(r=-0.72$ and $r=-0.71$, respectively). This may be related to the fact that acidity values and moisture content were higher in batches $B$ and $C$ (Table 1), since the titratable acidity and moisture of cheese markedly affects its rheology due to its influence on paracasein hydration. Hydration of paracasein decreases as the $\mathrm{pH}$ is reduced further to 4.6 (Creamer, Lawrence, \& Gilles, 1985), thus the casein aggregation increases, and the frequency dependence of the $G$ ' and $G$ ' diminishes (Table 3). 
Table 3. Power law parameters of equations 1 and 2 for the three batches of Cebreiro cheese at $20^{\circ} \mathrm{C}$

\begin{tabular}{|c|c|c|c|}
\hline & $\mathbf{A}$ & B & C \\
\hline Go'$^{\prime} \cdot\left(k P a \cdot s^{n}\right)$ & $23.7 \pm 5.9^{\mathrm{a}}$ & $23.7 \pm 6.6^{\mathrm{a}}$ & $25.3 \pm 9.1^{\mathrm{a}}$ \\
\hline n' & $0.149 \pm 0.001^{b}$ & $0.136 \pm 0.001^{\mathrm{a}}$ & $0.139 \pm 0.001^{\mathrm{a}}$ \\
\hline Go"'(kPa·s" & $7.3 \pm 1.5^{\mathrm{a}}$ & $6.8 \pm 1.8^{\mathrm{a}}$ & $7.6 \pm 2.7^{\mathrm{a}}$ \\
\hline n” & $0.170 \pm 0.004^{c}$ & $0.142 \pm 0.003^{b}$ & $0.151 \pm 0.003^{\circ}$ \\
\hline $\mathbf{r}^{2}$ & 0.9989 & 0.9993 & 0.9986 \\
\hline
\end{tabular}

${ }^{a}$ Values in the same file not followed by the same letter differed significantly $(\mathrm{P}<0.05)$.

The striking structural differences among the three batches are also quantifiable in terms of the quality factor $Q$, a parameter frequently used in mechanical oscillatory systems. It is a dimensionless magnitude that is related to the degree of damping of an oscillator. Taking into account the oscillatory character of frequency sweeps, using equations 1 and 2, the following Equation (4) was proposed to discriminate the rheological quality of different food protein gels (Campo-Deaño, Tovar, \& Borderías, 2010):

$$
Q=2 \pi \frac{G_{0}^{\prime}}{G_{0}^{\prime \prime}} \omega^{\left(n^{\prime}-n^{\prime \prime}\right)}
$$

The $Q$ factor unifies parameters that provide different kinds of structural information: $G_{0}{ }^{\prime}$ and $G_{0}{ }^{\prime \prime}$ are related to the strength of the intermolecular interactions and $n$ ' and $n$ ' to the extent and stability of the protein network.

The $Q$ values were higher $(\mathrm{P}<0.05)$ in batches $B$ and $C$ than in batch $A$ (Figure 2), thus confirming that the casein networks have better gel characteristics in samples with higher titratable acidity and higher water content (Table 1). According to this, the $\mathrm{Q}$ factor was negatively and significant correlated $(\mathrm{P}<0.05)$ with TS (Table 5), since if a total solid diminishes, the fluidity of protein networks increases, then the viscous losses decrease and $Q$ increases. This result is consistent with the lower tan $\delta$ values in batches $B$ and $C$ determined by stress sweeps (Table 2); in these batches less $C C P$ was solubilized and the interactions increased as a result of the greater number of crosslinks (Lucey et al., 2003), thus the elastic character of the different samples increased and loss tangent values decreased.

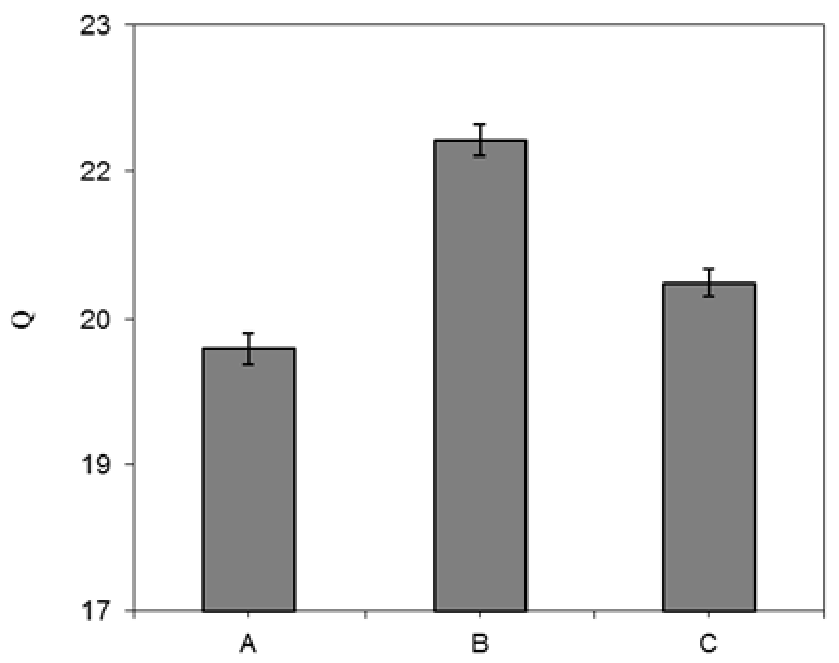

Figure 2. Comparison of quality factor values for the three batches of Cebreiro cheese at $1 \mathrm{~Hz}$ and $20^{\circ} \mathrm{C}$

\subsubsection{Fractal Dimension}

The concept of fractal geometry is a quantitative tool used to measure the complexity of gel structures by showing a pattern of self-similarity characterized by non-integer dimension: the fractal dimension $\left(D_{f}\right)$. This 
parameter reflects the degree of polymerization in the three-dimensional casein network, since casein micelles become aggregated on acidification, by charge neutralization, to form networks of chains and clusters (Heertje, Visser, \& Smits, 1985). The fractal dimension can be calculated by rheological equations, starting from the power law frequency dependence of the complex modulus $n$ values (Equation 3). The structure may be described by a fractal dimension $D_{f}$ according to Equation 5 (Campo-Deaño et al., 2009):

$$
n=\frac{d\left(d+2-2 D_{f}\right)}{2\left(d+2-D_{f}\right)}
$$

where $d$ is the spatial dimension, and $D_{f}$ relates the molecular weight of the protein aggregate, $M$, to its cluster size $R$, by $R^{D f} \approx M$ (Celli et al., 2007). In general, when there is sufficient protein aggregation, the fractal aggregates grow until they occupy the entire liquid volume, at which point a three-dimensional continuous network or gel is formed.

Fractal dimension values were derived from Equation 5 to evaluate the different reticular extension of casein networks in batches $A, B$ and $C$. The three $D_{f}$ values calculated $(\approx 2.4)$ are similar to those reported for other acid casein gels (Bremer, Van Vliet, \& Walstra, 1989).

The value of parameter $D_{f}$ at $20^{\circ} \mathrm{C}$ was higher and similar in batches $B$ and $C$, in which the titratable acidity values were undistinguishable $(\mathrm{P}<0.05)$ (Table 1$)$. The higher $D_{f}$ values can be explained by taking into account that, when the $\mathrm{pH}$ decreases from 4.5 to 4 , stronger gels are produced as a result of charge neutralization (Xiong, Aguilera, \& Kinsella, 1991), leading to the formation of chains and clusters that are linked together to form more dense clusters of aggregated casein particles, which in turn aggregate to form a fractal aggregate. Also, parameter $D_{f}$ was positively and significantly correlated $(\mathrm{P}<0.01)$ with titratable acidity values (Table 5$)$. It was recently suggested that cheese texture is determined by the balance between repulsive and attractive interactions in the caseins that form the protein network. Attractive interactions include $C C P$ crosslinks, hydrogen bonds, and hydrophobic interactions (Lucey et al., 2003). In batches $B$ and $C$ there was an increase in attractive interactions since the moisture contents were higher than in batch $A$ (Table 1), and demineralization lower, hence the number of $C C P$ crosslinks among the casein micelles was higher, thus allowing reticular expansion and higher $D_{f}$.

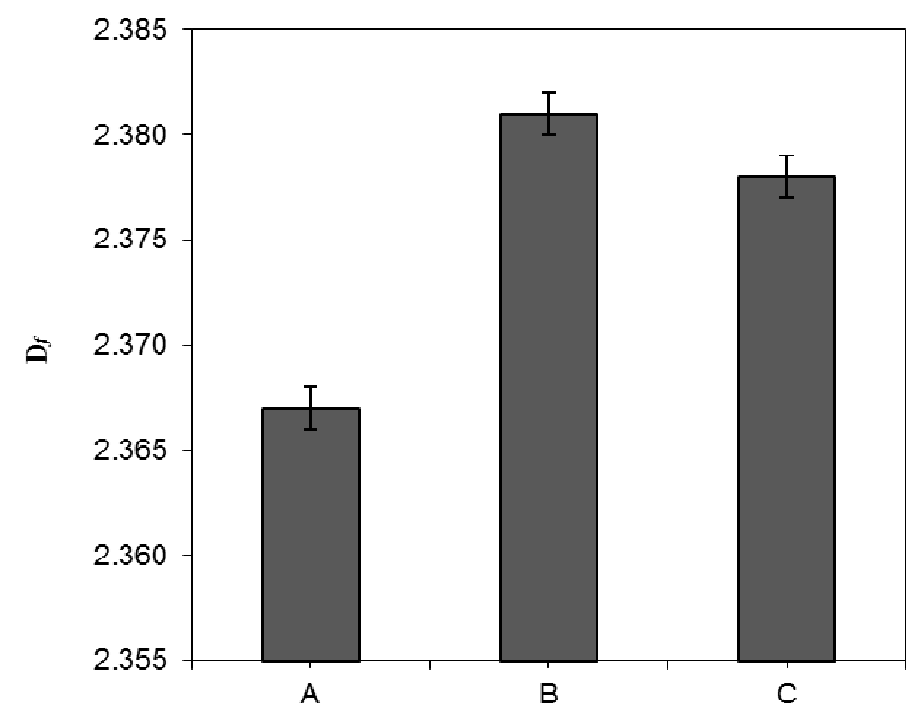

Figure 3. Comparison of fractal dimensions for the three batches of Cebreiro cheese at $20^{\circ} \mathrm{C}$

\subsection{Oscillatory Tests at Small Strain at Different Temperatures}

The complex viscosity $\left(\mu^{*}\right)$ values for the three batches at $0.5 \%$ strain are shown in Table 4 . A decrease in complex viscosity was observed with increasing temperature. For each cheese, a plot of $\mu^{*}$ against the reciprocal of absolute temperature (1/T) produced a straight line that followed the Arrhenius equation (Equation 6): 


$$
\mu^{*}=A \cdot e^{E a / R T}
$$

Where $A$ is the pre-exponential factor, $\mathrm{E}_{\mathrm{a}}$ is the activation energy, and $\mathrm{R}$ is the gas constant $(8.314 \mathrm{~J} / \mathrm{mol} \cdot \mathrm{K})$. The Ea values were obtained from the data in Table 4 and using equation $6(45 \pm 11,61 \pm 5$ and $59 \pm 7 \mathrm{~kJ} / \mathrm{mol}$ for batches $A, B$ and $C$ respectively). The higher $\mathrm{E}_{\mathrm{a}}$ values for the $B$ and $C$ batches indicate that their micellar networks break down less easily than in $A$ batch (Tunick, Nolan, Shieh, Basch, \& Thompson, 1990). This is consistent with the higher values of parameters $D_{f}$ and $Q$, since their casein networks possess a large number of attractive interactions, and hence higher reticular extent and elastic character (Figures 2 and 3). Moreover, parameters $Q$ and $D_{f}$ were positively and significantly correlated $(\mathrm{P}<0.05)$ with proteolysis data (Table 5$)$. This is in apparent contradiction with the physical meaning of the three rheological parameters. However taking into account the values of the different nitrogen fractions (Table 1), it is possible to affirm that Cebreiro cheese undergoes a low level of proteolysis, which does not disturb the structural integrity of their micellar networks, resulting in lower and statistically undistinguishable values of PTASN in batches $A, B$ and $C$ (Table 1).

Table 4. Values of complex viscosity $(\mathrm{kPa} \cdot \mathrm{s})$ at different temperatures for the three batches of Cebreiro cheese at $1 \mathrm{~Hz}$

\begin{tabular}{llll}
\hline $\mathbf{T}\left({ }^{\mathbf{0}} \mathbf{C}\right)$ & $\mathbf{A}$ & $\mathbf{B}$ & $\mathbf{C}$ \\
\hline $\mathbf{2 0}$ & $5.0 \pm 1.0$ & $5.1 \pm 1.0$ & $4.7 \pm 1.3$ \\
$\mathbf{2 2}$ & $3.4 \pm 0.9$ & $3.9 \pm 0.6$ & $3.4 \pm 0.5$ \\
$\mathbf{2 4}$ & $3.7 \pm 0.7$ & $3.7 \pm 0.6$ & $3.4 \pm 0.8$ \\
$\mathbf{2 6}$ & $3.57 \pm 0.5$ & $3.2 \pm 0.6$ & $3.0 \pm 0.5$ \\
$\mathbf{2 8}$ & $3.07 \pm 0.4$ & $2.6 \pm 0.5$ & $2.4 \pm 0.3$ \\
$\mathbf{3 0}$ & $2.26 \pm 0.3$ & $2.1 \pm 0.3$ & $1.9 \pm 0.3$ \\
\hline
\end{tabular}

Table 5. Some significant correlation coefficients obtained from the correlation matrix for variables analysed in Cebreiro cheese $(\mathrm{n}=12)$

\begin{tabular}{ll}
\hline Variables & $\mathbf{r}$ \\
\cline { 2 - 2 } TS - Titratable acidity & $-0.72^{* *}$ \\
TS $-\mathrm{WSN}$ & $-0.77^{* *}$ \\
$\mathrm{TS}-\mathrm{TCASN}$ & $-0.87^{* * *}$ \\
$\mathrm{TS}-\mathrm{Q}$ & $-0.68^{*}$ \\
$\mathrm{pH}-\mathrm{n}$, & $0.71^{*}$ \\
$\mathrm{pH}-\mathrm{n}$, & $0.64^{*}$ \\
$\mathrm{pH}-\mathrm{D}_{\mathrm{f}}$ & $-0.71^{*}$ \\
Titratable acidity $-\mathrm{n}$, & $-0.72^{* *}$ \\
Titratable acidity $-\mathrm{n}$, & $-0.71^{* *}$ \\
Titratable acidity $-\mathrm{Q}$ & $0.60^{*}$ \\
Titratable acidity $-\mathrm{D}_{\mathrm{f}}$ & $0.73^{* *}$ \\
TCASN $-\mathrm{WSN}$ & $0.82^{* *}$ \\
TCASN $-\mathrm{n}$, & $-0.75^{* *}$ \\
TCASN $-\mathrm{n}$, & $-0.88^{* * *}$ \\
TCASN $-\mathrm{Q}$ & $0.77^{* *}$ \\
TCASN $-\mathrm{D}_{\mathrm{f}}$ & $0.78^{* *}$ \\
Ea $-\mathrm{D}_{\mathrm{f}}$ & $0.71^{* *}$ \\
Ea $-\mathrm{Q}$ & $0.73^{* *}$ \\
\hline
\end{tabular}

$* \mathrm{P}<0.05 ; * * \mathrm{P}<0.01 ; * * * \mathrm{P}<0.001$. 


\section{Conclusions}

A detailed physicochemical and rheological study of Cebreiro cheese is presented. The viscoelastic parameters of all cheese samples, and consequently their textural properties, were significantly affected by the titratable acidity values and total solid contents. Several chemical parameters, such as titratable acidity, moisture content and nitrogen fractions were found to be correlated with different physical magnitudes, such as quality factor and fractal dimension.

Although the firmness of all samples was high and similar, the structural influence of demineralization effect in casein micelles was observed, in terms of the behaviour of the loss tangent in their fractal aggregates. Taking into account the overall physicochemical and dynamic oscillatory measurements, it was concluded that batches $B$ and $C$ possess better gel properties than batch $A$. Further research should focus on analyze the effect of heating process on the viscoelasticity under small deformations.

\section{Acknowledgments}

This work was financially supported by the Xunta de Galicia (CONSOLIDATION AND STRUCTURING OF COMPETITIVE RESEARCH UNITS - STRATEGIC GROUPS MODE, 2009).

\section{References}

Antoniou, K. D., Petridis, D., Raphaelides, S., Ben Omar, Z., \& Kesteloot, R. (2000). Texture Assessment of $\begin{array}{llllll}\text { French cheeses. Journal of Food } & \text { Science, } & \text { 65, }\end{array}$ http://dx.doi.org/10.1111/j.1365-2621.2000.tb15974.x

AOAC. (1980). Official Methods of Analysis (13th ed.). Whashington, USA: Association of Official Analytical Chemists Inc.

Barnes, H. A., Hutton, J. F., \& Walters, K. (1998). An Introduction to Rheology (pp. 37-55). Oxford, UK: Elsevier.

Bremer, L. G. B., Van Vliet, T., \& Walstra, P. (1989). Theoretical and experimental study of the fractal nature of the structure of casein gels. Journal of the Chemical Society Faraday Transactions, 85, 3359-3372. http://dx.doi.org/10.1039/F19898503359

Campo-Deaño, L., \& Tovar, C. (2009). The effect of egg albumen on the viscoelasticity of crab sticks made from Allaska Pollock and Pacific Whiting surimi. Food Hydrocolloids, 23, 1641-1646. http://dx.doi.org/10.1016/j.foodhyd.2009.03.013

Campo-Deaño, L., Tovar, C. A., \& Borderías, J. (2010). Effect of several cryoprotectants on the physicochemical and rheological properties of suwari gels from frozen squid surimi made by two methods. Journal of Food Engineering, 97, 457-464. http://dx.doi.org/10.1016/j.jfoodeng.2009.11.001

Castillo, M., Lucey, J. A., \& Payne, F. A. (2006). The effect of temperature and inoculum concentration on rheological and light scatter properties of milk coagulated by a combination of bacterial fermentation and chymosin. Cottage cheese-type gels. International Dairy Journal, 16, 131-148. http://dx.doi.org/10.1016/j.idairyj.2005.02.005

Celli, J. P., Turner, B. S., Afdhal, N. H., Ewoldt, N. H., McKinley, G. H., Bansil, R., \& Erramilli, S. (2007). Rheology of gastric mucin exhibits a pH-dependent sol-gel transition. Biomacromolecules, 8, 1580-1586. http://dx.doi.org/10.1021/bm0609691

Clark, A. H., \& Ross-Murphy, S. B. (1987). Structural and mechanical properties of biopolymer gels. Advances in Polymer Science, 83, 57-192. http://dx.doi.org/10.1007/BFb0023332

Creamer, L. K., Lawrence, R. C., \& Gilles, J. (1985). Effect of acidification of cheese milk on the resultant Cheddar cheese. New Zeland Journal Dairy Science Technology, 20, 185-203.

Damodaran, S., \& Paraf, A. (1997). Food Proteins and their Applications (pp. 216-220). New York: Marcel Dekker, Inc.

Diario Oficial de Galicia (DOG). (2004). Orden del 21 de diciembre de 2004 por la que se aprueba el Reglamento de la Denominación de Origen protegida Cebreiro y de su consejo regulador, Spain.

Fernández-Abalat, M. P., Fernández, M. A., Cobos, A., \& Méndez, J. (2006). Influence of ultrafiltration of the acidified coagulum and subsequent treatments of the concentrate on rheological characteristics of fresh lactic cheese. Milchwwissenschaft, 61, 297-299. 
FIL-IDF. (1982). Cheese and processed cheese. Determination of the total solids content. Standard 4A. International Dairy Federation. Brussels, Belgium.

FIL-IDF. (1993). Cheese and processed cheese. Determination of nitrogen content (Kjeldahl method). Standard 20B: International Dairy Federation. Brussels, Belgium.

Fresno, J. M., Prieto, B., Urdiales, R., Martín Sarmiento, R., \& Carballo, J. (1995). Mineral content of some Spanish cheese varieties. Differentiation by source of milk and by variety from their content of main and trace elements. Journal of the Science of Food and Agriculture, 69, 339-345. http://dx.doi.org/10.1002/jsfa.2740690310

Gabriele, D., de Cindio, B., \& D’Antona, P. (2001). A weak gel model for foods. Rheologica Acta, 40, $120-127$. http://dx.doi.org/10.1007/s003970000139

Heertje, L. Visser, J., \& Smits, P. (1985). Structure formation in acid milk gels. Food Microstructure, 4, 267-273.

Horne, D. S. (1998). Casein interactions: Cating light on the Black Boxes, the structure in dairy products. International Dairy Journal, 8, 171-177. http://dx.doi.org/10.1016/S0958-6946(98)00040-5

Kuchroo, C. N., \& Fox, P. F. (1982). Soluble nitrogen in Cheddar cheese: comparison of extraction procedures. Milchwissenschaft, 37, 651-653.

Lafuente, M., Carballo, J., González Prieto, J., \& Martín Sarmiento, R. (1995). Biochemical characteristics of two types of unripe Spanish cow's milk cheese (Cebreiro and Pasiego varieties). Food Chemistry, 52, 23-28. http://dx.doi.org/10.1016/0308-8146(94)P4176-G

Lawrence, R. C., Creamer L. K., \& Gilles, J. (1987). Texture development during cheese ripening. Journal of Dairy Science, 70, 1748-1760. http://dx.doi.org/10.3168/jds.S0022-0302(87)80207-2

Lucey, J. A. (2002). Formation and physical properties of milk protein gels. Journal of Dairy Science, 85, 281-294. http://dx.doi.org/10.3168/jds.S0022-0302(02)74078-2

Lucey, J. A., \& Fox, P. F. (1993). Importance of calcium and phosphate in cheese manufacture: A review. Journal of Dairy Science, 76, 1714-1724. http://dx.doi.org/10.3168/jds.S0022-0302(93)77504-9

Lucey, J. A., Johnson, M. E., \& Horne, D. S. (2003). Perspectives on the basis of the rheology and texture properties of cheese. Journal of Dairy Science, 86, 2725-2743. http://dx.doi.org/10.3168/jds.S0022-0302(03)73869-7

Lucey, J. A., Mishra, R., Hassan, A., \& Johnson, M. E. (2005). Rheological and calcium equilibrium changes during ripening of Cheddar cheese. International Dairy Journal, 15, 645-653. http://dx.doi.org/10.1016/j.idairyj.2004.08.018

Rao, M. A. (2007). Rheology of Fluid and Semisolid Foods (pp. 339-402). New York, USA: Springer Science, Business Media.

Ross-Murphy, S. B. (1984). Rheological methods. In H. W. Chan (Ed.), Biophysical Methods in Food Research (pp. 138-199). London, UK: Blackwell Scientific Publications.

Sheehan, J. J., \& Guinee, T. P. (2004). Effect of pH and calcium level on the biochemical, textural and functional properties of reduced fat Mozzarella cheese. International Dairy Journal, 14, 161-172. http://dx.doi.org/10.1016/S0958-6946(03)00167-5

Swaisgood, H. E. (1993). Review and update of casein chemistry. Journal of Dairy Science, 76, 3054-3061. http://dx.doi.org/10.3168/jds.S0022-0302(93)77645-6

Tovar, C. A., Franco, I., Riveiro, Y., Romaní, L., \& Carballo, J. (2004a). Changes in viscoelastic properties during the ripening of Arzúa-Ulloa cheese. Effect of proteolysis. Journal of Texture Studies, 35, 293-309. http://dx.doi.org/10.1111/j.1745-4603.2004.tb00839.x

Tunick, M. H., Nolan, E. J., Shieh, J. J., Basch, J. J., \& Thompson, M. P. (1990). Cheddar and Chesire cheese rheology. Journal of Dairy Science, 73, 1671-1675. http://dx.doi.org/10.3168/jds.S0022-0302(90)78841-8

Watkinson, P., Coker, C., Crawford, R., Dodds, C., Johnston, K., McKenna, A., \& White, N. (2001). Effect of cheese $\mathrm{pH}$ and ripening time on model cheese textural properties and proteolysis. International Dairy Journal, 11, 455-464. http://dx.doi.org/10.1016/S0958-6946(01)00070-X

Xiong, Y. L., Aguilera, J. M., \& Kinsella, J. E. (1991). Emulsified milk fat effects on rheology of acid-induced milk gels. Journal of Food Science, 56, 920-925. http://dx.doi.org/10.1111/j.1365-2621.1991.tb14606.x 